\title{
CORAL INFANTIL DO IFRN CIDADE ALTA: EM CADA CANTO, UMA VIDA; EM CADA VIDA, UM ENCANTO
}

Maria de Lourdes Lima de Souza Medeiros ${ }^{1}$

\section{RESUMO}

O Projeto de Extensão "Coral Infantil do IFRN Cidade Alta" é aberto à comunidade, atendendo principalmente crianças de 8 a 14 anos que residem em bairros econômica e socialmente carentes. Este projeto deu origem ao grupo Coral Infantil do referido Campus, cuja atuação vem se solidificando cada vez mais, tendo já participado de várias apresentações internas (no âmbito do IFRN) e externas (na comunidade). Entre os principais objetivos, estão a ampliação da percepção da criança coralista por meio de um repertório musical variado, que englobe músicas de diversos gêneros e de outras culturas, desde que estejam dentro das possibilidades técnicas do grupo; a conscientização do aluno a respeito da utilização de sua voz como um instrumento musical, ensejando a descoberta de suas potencialidades vocais; e o desenvolvimento da musicalidade do aluno através de exercícios de som, ritmo, coordenação motora e criatividade. O desenvolvimento do espírito crítico e estético é uma consequência da vivência destes elementos.

Palavras-chave: coral infantil; educação musical.

\section{INTRODUÇÃO}

O Coral Infantil do IFRN Cidade Alta, criado por meio de um Projeto de Extensão iniciado em maio de 2010, vem se mantendo como um grupo cultural permanente, sob a coordenação e a regência da autora deste trabalho. 0 Projeto "Coral Infantil do IFRN Cidade Alta" é aberto à comunidade, atendendo principalmente crianças, na faixa etária de 8 a 14 anos, residentes de bairros econômica e socialmente carentes.

Entre os objetivos, a atividade do Coral Infantil procura ampliar a percepção da criança pelo conhecimento de um variado repertório musical que englobe músicas de diversos gêneros, valorizando também a música de outras czulturas, sempre dentro das possibilidades técnicas do grupo; conscientizar o aluno sobre a utilização da sua voz como um instrumento musical e sobre como fazer bom uso da mesma, ensejando a descoberta de suas potencialidades vocais; e desenvolver a musicalidade do aluno através de exercícios de som, ritmo, coordenação motora e criatividade e, como consequência da vivência destes elementos, gerar o espírito crítico e estético na criança. Aliando-se a esses objetivos, sabemos que a música é uma atividade socializadora e que a sua prática é importante para o desenvolvimento da identidade, da autonomia, 
da autoestima e do conhecimento de si próprio, proporcionando autoconfiança e estimulando a criança a enfrentar desafios. Joly (in SESC São Paulo, 1997, p. 10) afirma que "canções, estórias, jogos e danças estabelecem a fundamentação para o amadurecimento social, emocional, físico e cognitivo da criança. Música também é um meio de fazer a criança participar de atividades de grupo. E cantar é sempre uma experiência prazerosa para a criança".

\section{COMENTÁRIOS SOBRE AS ATIVI- DADES E OS ENSAIOS}

Na sua ainda curta existência, o Coral Infantil vem tendo uma presença marcante nas atividades culturais do Campus Cidade Alta, bem como em toda a Instituição e fora dela. O Coral Infantil já participou de diversos eventos, destacando-se as suas apresentações no Encontro de Corais da Cidade do Natal - ENCONAT (em 2010 e 2013), no I Seminário Internacional Luso-Brasileiro de Ciências da Educação, na 1a Feira de Ciência e Tecnologia do PFRH-IFRN, na Exposição Científica, Tecnológica e Cultural - EXPOTEC, no I Simpósio de Extensão e Tecnologia do IFRN, entre outras.

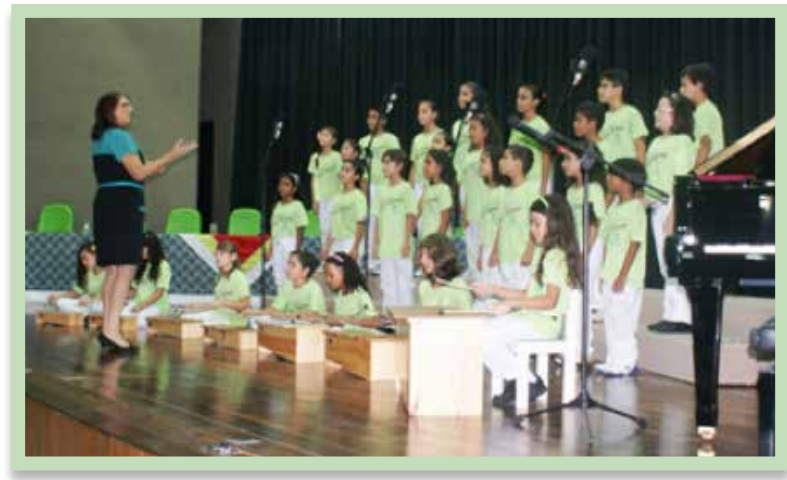

Figura 1: apresentação do Coral na 1a Feira de Ciência e Tecnologia do PFRH-IFRN (Foto: Alberto Medeiros)

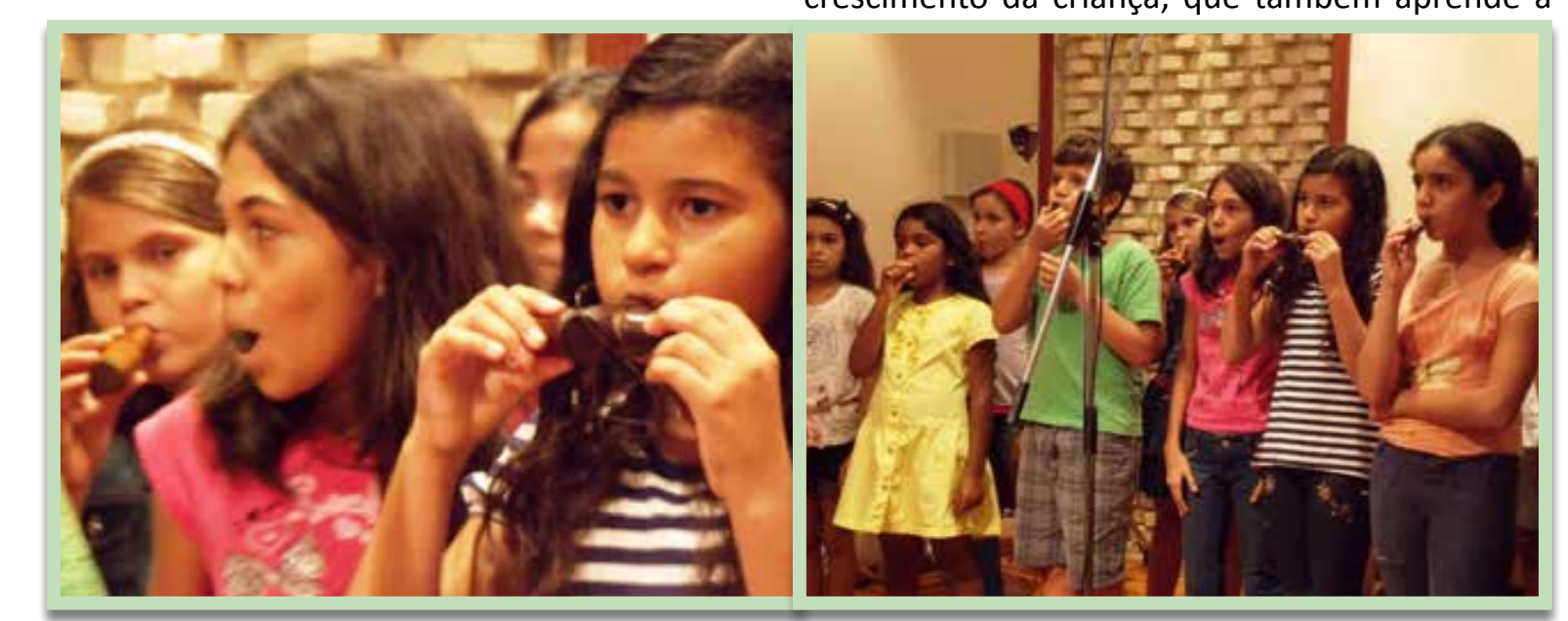

Figura 2: crianças explorando sons de apitos (Fotos: Jonas Buarque)
A dinâmica de ensaio do Coral Infantil do IFRN é semelhante à de todo coral profissional, incluindo exercícios de integração, exercícios técnicos, de aquecimento vocal, de relaxamento e de conscientização das partes do corpo, de alongamento, de respiração, de percepção musical. A diferença é que tudo é feito com muita ludicidade, de forma que a criança tenha prazer de executar cada atividade sem sentir o peso de exercícios que poderiam se tornar enfadonhos, repetitivos e cansativos, se não tivessem este caráter lúdico. Desta forma, as crianças vão ampliando as suas potencialidades vocais através de exercícios que Ihes deem prazer.

Com pouco tempo de ingresso no coral, já se percebe uma mudança na voz da criança. Muitas vezes, ela chega ao grupo com uma tendência a usar a voz de forma "gritada", modelo muitas vezes transmitido pela mídia, que a estimula a gritar, a cantar "de garganta". Porém, logo vai percebendo a forma correta de colocar a voz, conscientizandose da importância dos exercícios de aquecimento e de técnica aplicada ao repertório que está sendo trabalhado, bem como de que fazer mau uso da voz pode causar sérios danos ao aparelho vocal. Com o tempo, as próprias crianças cobram estes exercícios.

Certa vez, quando comecei o ensaio com uma música que, por estar em uma região vocal cômoda, já servia como aquecimento vocal, uma criança disse: "Professora, não vai fazer o aquecimento?" Tive, então, que explicar o porquê de já ter começado com aquela música: que, por natureza, ela favorecia o aquecimento vocal. No entanto, fiquei feliz pelo grau de consciência que esta criança havia adquirido.

O senso estético das crianças vai também se aprimorando e, quando chegam as novatas, as antigas logo percebem a diferença e manifestam isso de forma verbal. Tudo isso propicia o crescimento da criança, que também aprende a 
respeitar as diferenças, a exercitar a paciência. No livro "Canto, Canção, Cantoria", do SESC São Paulo (1997, p. 69), afirma-se que "a capacidade da criança não deve ser subestimada. Ela possui um senso estético e crítico aguçado e seu aprimoramento é função da atividade artística".

Certa ocasião, estávamos trabalhando uma música na qual um determinado trecho é aberto para improvisações com sons da natureza e principalmente sons de pássaros. Apresentei para as crianças alguns apitos com sons de pássaros e elas puderam explorar os sons dos mesmos e fazer uma apreciação crítica destes sons.

Depois, juntos, decidimos que os sons criados e produzidos por elas próprias estavam soando bem melhor do que os dos apitos. Mesmo se as crianças estavam gostando da novidade de utilizar os apitos, puderam perceber que os sons que elas criavam soavam bem mais cheios de emoção, possibilitando a exploração de diversos timbres e texturas e intensidades variadas, tornando a música mais expressiva. Puderam ouvir umas às outras, dando espaço para que o som emitido pelo colega se sobressaísse quando reconheciam que este se mostrava mais interessante e adequado para o momento.

Um ponto muito forte neste trabalho é o amor à criança e à música. Muito importante é saber escutar. As crianças chegam ao ensaio com seus anseios, carregando, muitas vezes problemas familiares dos mais diversos. Elas também trazem novidades boas que querem compartilhar para o grupo e, enquanto não o fazem, ficam agitadas e não se concentram. Paulo Freire (2000, p. 135) explica o sentido do "escutar": "disponibilidade permanente por parte do sujeito que escuta para a abertura à fala do outro, ao gosto do outro, às diferenças do outro". Isto não significa que aquele que escuta deva se anular, pois a escuta verdadeira não o diminui em nada; pelo contrário, quanto mais se escuta o outro, mais fértil é o terreno para que as atividades se desenvolvam de forma plena. É sempre um exercício ter o coração pronto para escutar as crianças, pois muitas vezes o cumprimento das atividades, a agenda de apresentações, o prazo para cumprir o repertório podem impedir o professor de descobrir que, abrindo esse espaço, não se perde nada, muito pelo contrário, ganha-se em qualidade, deixa-se a criança mais pronta para aproveitar o ensaio em todas as suas etapas. Desta forma, as crianças se sentem realmente amadas e acolhidas, o que se reflete em seus rostinhos felizes, e se esvaziam para acolher novos conteúdos. Desfrutando desse prazer que as crianças sentem, inspirei-me em fazer uma música intitulada "O tempo passou tão depressa", que elas cantam com muito gosto após a "aula coral". A música diz: "o tempo passou tão depressa / que eu nem senti passar, / e a aula que foi tão boa / agora vai terminar", e finaliza acrescentando "vou pra casa com vontade de ficar".

Na maioria das vezes, fazemos, em conjunto, uma análise crítica após uma apresentação. Eis o que disseram algumas crianças nessas oportunidades: "foi boa a apresentação no IF Central porque tinha espaço para fazer a coreografia"; "gostei da apresentação no IF Cidade Alta porque estávamos perto de onde a gente ensaia"; "não gostei porque tinha gente conversando na hora da flauta"; "a gente estava menos nervosa na apresentação do IF Cidade Alta, por isso foi melhor". Muitas outras observações são feitas por elas a respeito do comportamento dos colegas e também é avaliada a interpretação das músicas.

\section{CONCLUSÃO}

O canto coral infantil, pelo seu valor educativo e socializador, é uma atividade que vem cada vez mais se difundindo. É importante, para exercer esta atividade, além dos conhecimentos de música por parte do responsável pelo coral, conhecer a voz infantil e as suas características, respeitar o limite vocal da criança e saber qual é a região vocal em que a voz infantil tem maior brilho e volume. Muita gente que lida com a voz infantil, sem esse conhecimento, não extrai da voz infantil toda a beleza, todo o brilho e potencial que pode ser explorado, fazendo a criança cantar com a voz grave, atingindo assim a sua região de fala e, desta forma, não obtém bons resultados artísticos e estéticos.

O Coral Infantil do IFRN - Campus Cidade Alta já se constitui como um grupo que faz a diferença na cidade de Natal. Recentemente, gravou um CD que será lançado em setembro de 2014 juntamente com um livro contendo as partituras das músicas, que são de autoria da regente do Coral, e também as indicações pedagógicas que irão auxiliar o professor de música nas suas atividades em sala de aula. A gravação do $C D$ e a publicação desse livro se tornaram possíveis a partir da realização do projeto "Repertório didático para o ensino da música: publicação de repertório e formação docente", aprovado pelo Edital № 2 do Programa de Extensão Universitária - PROEXT 2013 - MEC/SESu e financiado pela SETEC. Pretendemos, ainda, como continuação deste Projeto, oferecer um curso de formação para 
professores de escolas públicas do Rio Grande do Norte que lecionam música na Educação Básica.

Além disso, o Projeto "Coral Infantil do IFRN Cidade Alta", com seu caráter de extensão, também abre espaço para que os alunos do Curso de Tecnologia em Produção Cultural do IFRN Cidade Alta tenham a oportunidade de atuar junto ao Coral nos eventos de que ele participa, cumprindo o papel previsto no Art. 31 da Resolução no 66/2009-IFRN: "As ações de extensão constituem um processo educativo, científico, artístico-cultural e desportivo que se articulam ao ensino e à pesquisa de forma indissociável, com o objetivo de intensificar uma relação transformadora entre o Instituto Federal de Educação, Ciência e Tecnologia do Rio Grande do Norte e a sociedade".

\section{REFERÊNCIAS}

SESC São Paulo. Canto, canção, cantoria: como montar um coral infantil. São Paulo: SESC, 1997.

FREIRE, Paulo. Pedagogia da autonomia: saberes necessários à prática educativa. Rio de Janeiro: Paz e Terra, 2000. 